\title{
Insulin analogs and cancer
}

\section{Laura Sciacca, Rosario Le Moli and Riccardo Vigneri *}

Endocrinology Section, Department of Clinical and Molecular Biomedicine, University of Catania, Garibaldi-Nesima Hospital, Catania, Italy

\section{Edited by:}

Annamaria Anita Livia Colao, University Federico II of Naples, Italy

Reviewed by:

Manuela Albertelli, Endocrinologia Università degli Studi di Genova, Italy

Gregory A. Kaltsas, National

University of Athens, Greece

*Correspondence:

Riccardo Vigneri, Endocrinologia,

Università di Catania, Ospedale

Garibaldi di Nesima, Via Palermo 636,

95122 Catania, Italy.

e-mail: vigneri@unict.it
Today, insulin analogs are used in millions of diabetic patients. Insulin analogs have been developed to achieve more physiological insulin replacement in terms of time-course of the effect. Modifications in the amino acid sequence of the insulin molecule change the pharmacokinetics and pharmacodynamics of the analogs in respect to human insulin. However, these changes can also modify the molecular and biological effects of the analogs. The rapidacting insulin analogs, lispro, aspart, and glulisine, have a rapid onset and shorter duration of action. The long-acting insulin analogs glargine and detemir have a protracted duration of action and a relatively smooth serum concentration profile. Insulin and its analogs may function as growth factors and therefore have a theoretical potential to promote tumor proliferation. A major question is whether analogs have an increased mitogenic activity in respect to insulin. These ligands can promote cell proliferation through many mechanisms like the prolonged stimulation of the insulin receptor, stimulation of the IGF-1 receptor (IGF$1 \mathrm{R}$ ), prevalent activation of the extracellular-signaling-regulated kinase (ERK) rather than the protein kinase B (PKB/AKT) intracellular post-receptor pathways. Studies on in vitro models indicate that short-acting analogs elicit molecular and biological effects that are similar to those of insulin. In contrast, long-acting analogs behave differently. Although not all data are homogeneous, both glargine and detemir have been found to have a decreased binding to receptors for insulin but an increased binding to IGF-1R, a prevalent activation of the ERK pathway, and an increased mitogenic effect in respect to insulin. Recent retrospective epidemiological clinical studies have suggested that treatment with long-acting analogs (specifically glargine) may increase the relative risk for cancer. Results are controversial and methodologically weak. Therefore prospective clinical studies are needed to evaluate the possible tumor growth-promoting effects of these insulin analogs.

Keywords: insulin analogs, insulin receptor, insulin receptor isoforms, IGF-1 receptor, cancer

\section{INTRODUCTION}

In addition to its typical metabolic effects, insulin is also a growth factor as shown by both in vitro and in vivo evidence. Insulin mitogenic effect was first believed to occur only at high concentrations via the IGF-1 receptor (IGF-1R), but it was later demonstrated to occur also at lower concentrations via its own receptor (Ish-Shalom et al., 1997). The mitogenic effects of hyperinsulinemia may be clinically relevant when considering the large number of subjects with endogenous compensatory hyperinsulinemia induced by insulin resistance or exogenous hyperinsulinemia due to the insulin treatment in diabetic patients (Vigneri et al., 2006, 2009). These concerns also apply to insulin analogs that have a molecular structure similar to that of insulin and interact with the insulin receptor, eliciting metabolic effects similar to those of insulin but either faster or more prolonged in order to better mimic the physiological condition and obtain an improved metabolic control (Vajo et al., 2001; Hirsch, 2005). Because of differences in the structure, insulin analogs may interact with receptors for insulin (IR) or IGF-1R in a slightly different way, activating metabolic and mitogenic pathways somewhat differently than native insulin (Drejer, 1992; Slieker et al., 1997; Ciaraldi et al., 2001; Vajo et al., 2001; Rakatzi et al., 2003; Jensen and De Meyts, 2009). For instance B10Asp, a single amino acid-substituted insulin analog that has increased affinity for both IR and IGF-1R as well as longer residence on the IR, was documented to have a potential oncologic risk (Hansen et al., 1996; Milazzo et al., 1997; Berti et al., 1998; Kurtzhals et al., 2000). Its biological characteristics were associated with increased occurrence of mammary tumors in B10Asp-treated female rats (Dideriksen et al., 1992; Ebeling et al., 1996). A 52-week exposure of rats to supraphysiological B10Asp concentrations revealed a dose-dependent increase in the occurrence of mammary tumors in female Sprague-Dawley rats (Drejer, 1992). Because of this concern all insulin analogs have been tested for their mitogenic potential during pre-clinical and clinical experimentation. Available data, however, are incomplete and the procedures used for checking B10Asp carcinogenic effect have not been repeated for all analogs (Smith and Gale, 2009).

In the last two decades accumulating evidences have established that insulin receptors are usually expressed at high levels in cancer cells, both in vitro and in vivo, and that these receptors directly mediate the biological effects of insulin, both metabolic and mitogenic (Papa et al., 1990; Frasca et al., 1999; Sciacca et al., 1999; Vella et al., 2002). Moreover, cells can express the IR in two isoforms (IR-A and IR-B), generated by alternative splicing of the insulin receptor gene that either includes or excludes 12 amino acid residues encoded by a small exon (exon 11) at the carboxyl 
terminus of the IR $\alpha$-subunit. The two IR isoforms are characterized by subtle differences in binding and signaling and by a major difference in IGF-2 binding: IR-A, but not IR-B, binds IGF-2 with high affinity and behaves as a second physiological receptor for this growth factor (Frasca et al., 1999). The two IR isoforms have slightly different biological characteristics (Mosthaf et al., 1990; Belfiore et al., 2009).

In each cell the relative abundance of IR isoforms is regulated by tissue-specific and differentiation-related factors that are mostly unknown (Belfiore et al., 2009). Moreover, it was observed that IR splicing is altered in cancer cells, causing aberrant (increased) expression of IR-A that was found to be the predominant IR isoform in a variety of carcinomas, including carcinomas of the breast, thyroid, ovarian, colon, lung (Frasca et al., 1999; Sciacca et al., 1999; Kalli et al., 2002; Vella et al., 2002). IR-A overexpression is not limited to malignancies derived from epithelial cells but also from mesenchymal cells like osteosarcoma (Avnet et al., 2009).

Given the high degree of homology, half-receptors (composed on one $\alpha$ - and one $\beta$-subunits) of the two IR isoforms can heterodimerize, leading to the formation of the hybrid IR-A/IR-B insulin receptors (Blanquart et al., 2008). Hybrid receptors bind IGF-2 with the same affinity than IR-A homodimers, whereas they bind IGF-1 with a lower affinity (Blanquart et al., 2008). In addition, most cells not only co-express the two IR isoforms but also the IGF-1R. Also these receptors have a high degree of homology with the insulin receptor and, on the basis of the availability of hemireceptors synthesized inside the cell, may randomly assembly to form hybrid receptor, i.e., receptors formed by heterologous hemireceptors of the IR isoforms and the IGF-1R (Belfiore et al., 2009).

Therefore, at least three heterotetramers (hybrids) are present in most cells: IR-A/IR-B, IR-A/IGF-1R, and IR-B/IGF-1R. Others hybrid receptors cannot be excluded considering the possible isoforms of IGF-1R (Moxham et al., 1989). Studies on hybrid receptors are scarce and incomplete due to the lack of adequate methodologies (Belfiore et al., 2009). Therefore, the metabolic and/or mitogenic responses of target cells (both normal and malignant) may also depend on the type and proportion of the different receptors that they express (Figure 1; Staiger et al., 2007; Shukla et al., 2009). To evaluate the specific contribution of each receptor to the effect of different ligands, the biological effects of insulin and its analogs were studied in cells expressing only one IR isoform (either A or B) or the IGF-1R (Sciacca et al., 2010; Sommerfeld et al., 2010). In addition, a number of studies have evaluated the proliferative effects of insulin analogs in different cancer cell lines (Liefvendahl and Arnqvist, 2008; Mayer et al., 2008; Shukla et al., 2009; Weinstein et al., 2009; Sommerfeld et al., 2010) and an increased mitogenic effect of long-acting analogs, relative to insulin, has been observed in some instances. In addition to being a more general effect, the mitogenic effect of insulin may be a problem in individuals with undiagnosed tumors, often present at an early stage, particularly when long-acting analogs and high doses are used, because cancer cells may be more responsive to insulin because of their increased IR expression with prevalently IR-A presence. Lately, retrospective epidemiologic studies have been published to investigate in diabetic patients the relative risk

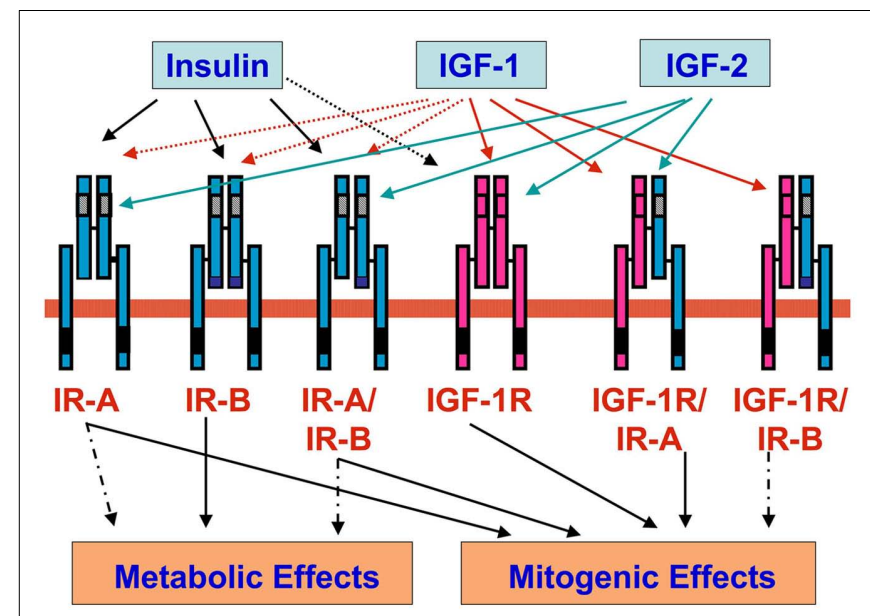

FIGURE 1 | Insulin receptors (IR-A and IR-B), IGF-1 receptor (IGF-1R), and hybrid receptors (IR-A/IR-B, IGF-1R/IR-A, and IGF-1R/IR-B). Insulin binds with high affinity to IR-A, IR-B, and hybrid receptors IR-A/IR-B (black arrow), whereas binds with low affinity to IGF-1R (black dotted arrow). IGF-1 binds with high affinity IGF-1R and hybrid receptors IGF-1R/IR-A and IGF-1R/IR-B (red arrow), whereas it binds with low affinity to IR-A, IR-B, and hybrid receptors IR-A/IR-B (red dotted arrow). IGF-2 binds with high affinity to IR-A, IGF-1R, and hybrid receptors IR-A/IR-B and IGF-1R/IR-A (green arrow). IR-A, IGF-1R, and hybrid receptors IR-A/IR-B and IGF-1R/IR-A predominantly mediate mitogenic effects. IR-B mediates prevalently metabolic effects.

for cancer incidence associated with the use of insulin and its analogs and an increased risk of cancer has been reported for glargine insulin by some studies (Colhoun, 2009; Currie et al. 2009; Dejgaard et al., 2009; Hemkens et al., 2009; Jonasson et al., 2009; Mannucci et al., 2010). These studies, however, have been heavily criticized for both methodology and analysis (Pocock and Smeeth, 2009; Johnson and Gale, 2010). However an increased risk of cancer associated with treatment with (high dose) of insulin and long-acting insulin analogs cannot be excluded on the basis of available clinical and experimental data.

\section{INSULIN ANALOGS}

Insulin analogs were developed in order to modify the pharmacokinetics of injected insulin to better mimic its endogenous secretion. By recombinant technology and site-directed mutagenesis, the insulin molecule has been modified to either prolong or shorten its action time. According to pharmacokinetics, insulin analogs can be divided into two major subgroups: short-acting and long-acting. In diabetic patients the use of insulin analogs has been shown to improve glycemic control without increasing hypoglycemic events in respect to regular or neutral protamine Hagedorn (NPH) insulin. Molecular modifications, however, may change the analog interaction with the IR, in terms of residence time of the ligand on the IR and post-receptor intracellular pathway activation. Also the binding affinity to IGF-1R, can be modified. As a result an imbalance between metabolic and mitogenic effects can occur (Figure 2).

Structure and characteristics of the insulin analogs are summarized in Table 1. 


\section{Long-acting insulin analogs}

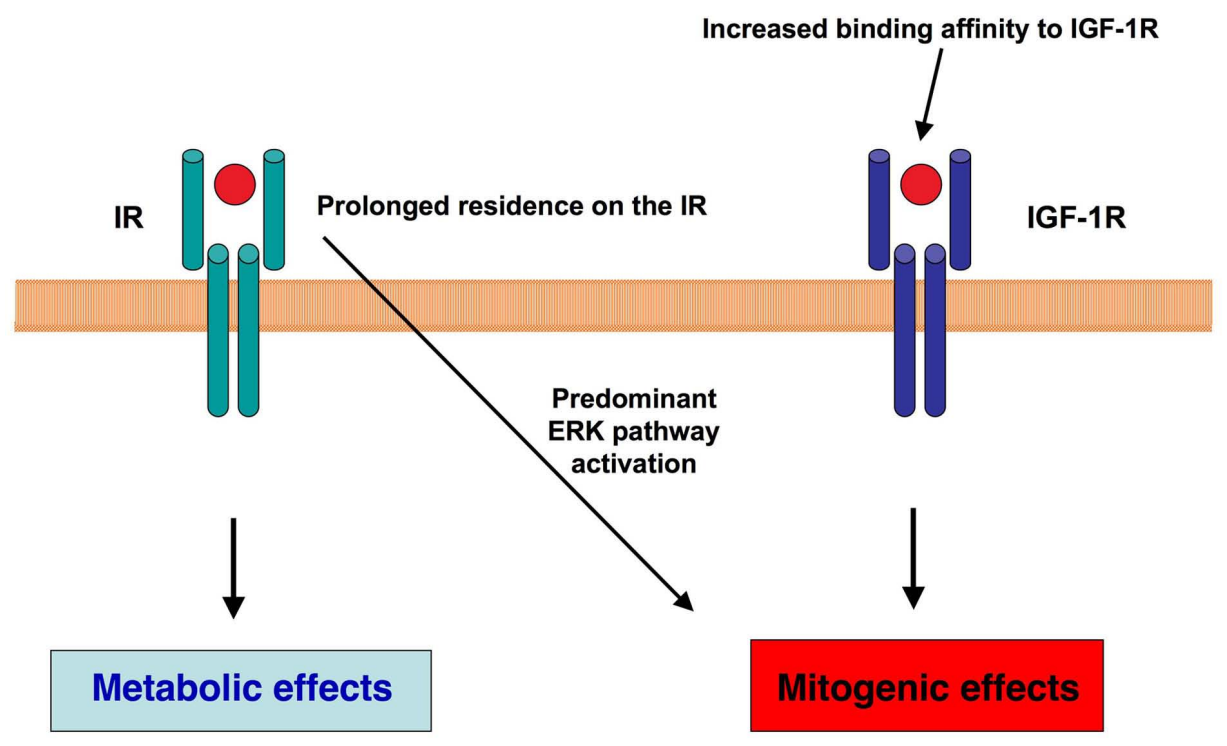

FIGURE 2 | Molecular mechanisms potentially involved in the mitogenic effects of long-acting insulin analogs. Two main molecular mechanisms

have been hypothesized to influence the balance of metabolic and mitogenic actions of long-acting insulin analogs: the longer residence of the ligand on the IR and/or an increased binding affinity of the insulin analog for IGF-1R may predominantly activate the mitogenic signaling.
Table 1 | Structure and characteristics of insulin analogs approved for clinical use.

\begin{tabular}{|c|c|c|}
\hline Analog & Structure & Characteristics \\
\hline Lispro & Lys(B28)Pro(B29) & Short-acting, rapidly absorbed \\
\hline Aspart & Asp(B28) & Short-acting, rapidly absorbed \\
\hline Glulisine & Lys(B3)Glu(B29) & Short-acting, rapidly absorbed \\
\hline Glargine & Gly(A21)Arg(B31)Arg(B32) & $\begin{array}{l}\text { Long-acting, smooth peak, low vari- } \\
\text { ability, injected as an acid solution }\end{array}$ \\
\hline Detemir & $\begin{array}{l}\text { Lys(B29)(N- } \\
\text { tetradecanoyl)des(B30) }\end{array}$ & $\begin{array}{l}\text { Long-acting, smooth peak, low vari- } \\
\text { ability, high affinity for albumin }\end{array}$ \\
\hline
\end{tabular}

\section{SHORT-ACTING INSULIN ANALOGS}

- Insulin Lispro was the first genetically engineered rapid-acting insulin analog to become available for clinical use. Insulin lispro (Lys $^{\text {B28 }}$, Pro ${ }^{\text {B29 }}$ human insulin) has been produced by recombinant DNA method. In insulin lispro molecule the B chain natural sequence of human insulin is reversed between proline at position 28 and lysine at position 29. This amino acid sequence alteration leads to a conformational shift in the C-terminus of the $\mathrm{B}$ chain, reducing the insulin ability to self-associate in solution (Brems et al., 1992; Holleman and Hoekstra, 1997), thus obtaining faster absorption and higher peak serum level after injection.

- Insulin Aspart $\left(\mathrm{Asp}^{\mathrm{B} 28}\right)$ is a recombinant human insulin analog obtained by changing insulin $\mathrm{B}$ chain proline at position 28 with the negatively charged aspartic acid. Pharmacokinetics and pharmacodynamics properties of insulin aspart are similar to those of insulin lispro (Plank et al., 2002).
- Insulin Glulisine ( Lys $^{\mathrm{B} 3}$, Glu ${ }^{\mathrm{B} 29}$ ) has been obtained by substituting the aspartic acid in position B3 with lysine and the lysine in position B29 with glutamine. These changes in the analog molecule reduce the rate of self-association when injected into the subcutaneous tissue, thus providing immediate biological availability (Becker, 2007).

After injection, the absorption profile of short-acting analogs reaches a peak that is approximately twice that of injected human insulin and is reached in approximately one half of the time. Binding affinity for the insulin receptor of lispro insulin (Slieker and Sundell, 1991), insulin aspart (Simpson and Spencer, 1999; Kurtzhals et al., 2000), and glulisine (Hennige et al., 2005) is similar to that of native insulin. Their duration of action is shorter (approximately two times than native insulin; Howey et al., 1994; Heinemann et al., 1998; Becker and Frick, 2008).

\section{LONG-ACTING INSULIN ANALOGS}

\section{Insulin glargine}

Insulin glargine $\left(\mathrm{Gly}^{\mathrm{A} 21}, \mathrm{Arg}^{\mathrm{B} 31}, \mathrm{Arg}^{\mathrm{B} 32}\right.$ human insulin) has been produced by recombinant DNA techniques, substituting the asparagine at position 21 in the A chain with glycine and adding two arginine residues to the $\mathrm{B}$ chain at positions 31 and 32 . Insulin glargine is soluble at acid $\mathrm{pH}$ but less soluble at neutral $\mathrm{pH}$, because its isoelectric point is at $\mathrm{pH} \sim 6.4-6.6$ (Bolli et al., 1999). Insulin glargine is injected subcutaneously as an acid solution ( $\mathrm{pH} 4.0)$ but in the neutral environment it precipitates and forms in the subcutaneous tissue a depot from which insulin is slowly released (Owens et al., 2000). The insulin receptor affinity of insulin glargine is similar to that of human insulin (Kurtzhals et al., 2000; Sciacca et al., 2010; Sommerfeld et al., 2010). Its duration of 
action is approximately $20 \mathrm{~h}$ at physiological doses (Lepore et al., 2000; Heise et al., 2002).

\section{Insulin detemir}

Insulin detemir [Lys ${ }^{\mathrm{B} 29}$ ( $N$-tetradecanoyl $)$ des(B30) human insulin] is not a real insulin analog but should rather be considered an insulin derivative because the $\mathrm{B} 30$ amino acid threonine is removed and a 14-carbon myristoyl fatty-acid is acylated to lysine at B29 (Markussen et al., 1996) obtaining a molecule that includes an insulin analog and a fatty-acid chain. After subcutaneous injection, insulin detemir avidly binds to albumin through the fattyacid chain and this reversible binding to albumin (approximately $98 \%$ of the amount of insulin detemir injected) on one hand prolongs the duration of detemir action and also reduces the biological availability of free insulin detemir. Although detemir is $98 \%$ bound to albumin, there is no evidence of detemir interaction with other albumin-bound proteins or differences in the analog kinetics in low albumin states (Kurtzhals et al., 1997). The insulin detemir affinity for the receptor, both in cultured and in vivo, is reduced due to the interference of albumin binding (Markussen et al., 1996; Sciacca et al., 2010). In clinical use, to obtain a similar biologic effect on blood glucose, insulin detemir must be administered to diabetic patients in the amount of $0.142 \mathrm{mg}$ of the analog per unit instead of $0.036 \mathrm{mg}$ per unit as for human native insulin and the other insulin analogs (3.9-fold higher detemir insulin molecule number than human insulin or other analog molecule number per injected unit).

\section{IN VITRO MITOGENIC EFFECTS OF INSULIN ANALOGS}

As already mentioned, molecular modifications present in insulin analogs may change their affinity for the IR and IGF-1R, their intracellular signaling and their biological effects. One critical item for approving the clinical use of insulin analogs has been the assessment of their mitogenic effects (growth-promoting activity) in benign and malignant cell lines in vitro.

\section{INSULIN ANALOGS INTERACTION WITH INSULIN AND IGF-1 RECEPTORS}

Studies on insulin (and its analogs) binding to each IR isoform are difficult because the large majority of cells express both IR isoforms and no direct measurement of the IR isoform proteins is available. By measuring the IR isoform transcript, cell models that naturally express only one IR isoform have been identified among malignant cells. More conveniently, engineered cell models have been constructed in non-transformed cells by expressing either only the IR-A or the IR-B isoform by transfecting with an expression vector containing the human cDNA of only one IR isoform (Sciacca et al., 2010; Sommerfeld et al., 2010). These are not perfect models because transfected receptors are often overexpressed and species specific native IR, even if at a very low level, are present in the cells used. Therefore, different models and different experimental procedures provided somewhat different results. However, overall data indicate that short-acting insulin analogs (aspart, lispro, and glulisine) bind to both IR isoforms with an affinity similar to that of native insulin or only slightly reduced (Table 2). In contrast, long-acting analogs have a reduced affinity for both IR isoforms and this is more evident for detemir, even when experimental conditions minimize albumin interference (Markussen et al., 1996; Kurtzhals et al., 2000; Sciacca et al., 2010; Sommerfeld et al., 2010).

Only few studies have measured the insulin analogs' dissociation from the two IR isoforms, an important parameter since insulin effects on target cells depend also from the ligand residency time on the receptor. Data are scarce and, again, not fully comparable because of the different experimental conditions. However, for short-acting analogs the dissociation from the IR isoforms appears

Table 2 | Insulin and insulin analog binding affinity for the two IR isoforms.

\begin{tabular}{|c|c|c|c|c|c|c|c|}
\hline \multirow[t]{2}{*}{ Cell model } & \multirow[t]{2}{*}{ Measurement } & \multirow[t]{2}{*}{ Insulin } & \multicolumn{3}{|c|}{ Short-acting analogs } & \multicolumn{2}{|c|}{ Long-acting analogs } \\
\hline & & & Aspart & Lispro & Glulisine & Glargine & Detemir \\
\hline \multicolumn{8}{|l|}{ IR-A } \\
\hline $\mathrm{R}^{-} / \mathrm{IR}-\mathrm{A}(1)$ & $\mathrm{EC}_{50}(\mathrm{nmol} / \mathrm{l})$ & $0.40 \pm 0.10$ & $0.60 \pm 0.15$ & $0.43 \pm 0.15$ & $0.61 \pm 0.03$ & $0.93 \pm 0.17$ & $0.90 \pm 0.26$ \\
\hline $\mathrm{CHO} / \mathrm{R}-\mathrm{A}(2)$ & $\mathrm{EC}_{50}(\mathrm{nmol} / \mathrm{l})$ & $0.49 \pm 0.04$ & $/ /$ & $/ /$ & $/ /$ & $0.83 \pm 0.08$ & $/ /$ \\
\hline BHK/IR-A (3) & $\%$ & 100 & $92 \pm 6$ & $84 \pm 6$ & $/ /$ & $86 \pm 3$ & $18 \pm 2$ \\
\hline \multicolumn{8}{|l|}{ IR-B } \\
\hline $\mathrm{R}^{-} / \mathrm{IR}-\mathrm{B}(1)$ & $\mathrm{EC}_{50}(\mathrm{nmol} / \mathrm{l})$ & $0.49 \pm 0.05$ & $0.70 \pm 0.25$ & $0.54 \pm 0.11$ & $0.74 \pm 0.25$ & $0.58 \pm 0.31$ & $14.01 \pm 1.83$ \\
\hline $\mathrm{CHO} / \mathrm{IR}-\mathrm{B}(2)$ & $\mathrm{EC}_{50}(\mathrm{nmol} / \mathrm{l})$ & $0.57 \pm 0.02$ & $/ /$ & $/ /$ & $/ /$ & $1.10 \pm 0.12$ & $/ /$ \\
\hline Rat-1/IR-B (4) & $\mathrm{EC}_{50}(\mathrm{nmol} / \mathrm{l})$ & $\approx 60$ & // & $/ /$ & $\approx 70$ & $/ /$ & $/ /$ \\
\hline Pig (5) & $\%$ & 100 & // & $/ /$ & $/ /$ & $/ /$ & $46 \pm 5$ \\
\hline
\end{tabular}

(1) $R^{-}$/IR-A: mouse embryo fibroblasts KO for IGF-1R transfected with human IR-A (Sciacca et al., 2010).

(2) CHO/IR-A: hamster ovary cells transfected with human IR-A (Sommerfeld et al., 2010).

(3) BHK/IR-A: WGA purified receptors from baby hamster kidney cells transfected with human IR-A (Kurtzhals et al., 2000).

(1) $R^{-}$/IR-B: mouse embryo fibroblasts KO for IGF-1R transfected with human IR-B (Sciacca et al., 2010).

(2) $C H O / I R-B$ : hamster ovary cells transfected with human IR-B (Sommerfeld et al., 2010).

(4) Rat-1/IR-B: rat fibroblasts transfected with human IR-B (Hennige et al., 2005).

(5) Pig, unknown which IR isoform (Markussen et al., 1996). 
similar to that of native insulin while the long-acting analogs have a slower dissociation rate (about 1.5-3 times longer) as indicated by studies where both cell models or solubilized receptors were used.

Data on IR isoform phosphorylation after exposure to insulin analogs are not only rare but also extremely difficult to compare because of the different experimental conditions (i.e., cell types, dose-response, time-course, etc.). However, when analogs were compared in the same cell model, both short-acting and longacting insulin analogs activated IR isoforms' phosphorylation in a similar manner than human insulin (Sciacca et al., 2010; Sommerfeld et al., 2010). In contrast to phosphorylation, differences between insulin and insulin analogs were evident at downstream post-receptor level. The results on AKT (a marker of the metabolic insulin signaling pathway) and extracellular-signaling-regulated kinase (ERK) phosphorylation (a marker of mitogenic insulin signaling pathway) after cell exposure to short-acting analogs indicated only subtle differences for either the amount or the time-course of the AKT and the ERK activation. In contrast, more marked differences relative to insulin were observed after receptor stimulation with long-acting analogs. Via IR-A both glargine and detemir activated AKT similarly to insulin and ERK more than insulin. Via IR-B both analogs activated AKT less than insulin and ERK similarly to insulin. In both cases the net result was that the two long-acting analogs produced an ERK/AKT activation ratio clearly shifted in favor of ERK (Sciacca et al., 2010).

At physiologic concentration insulin binding to the IGF-1R is minimal or absent and the mitogenic effects of insulin, once attributed to its interaction with the IGF-1R, are known to occur as an intrinsic characteristic of the IR activation. However, a serious concern with insulin analogs is whether the modified molecular structure may cause an increased affinity for the IGF-1R relative to native insulin and, as a consequence, an increased mitogenic effect.

The cancer risk associated with the IGF-1R expression and activation is well recognized (Furstenberger and Senn, 2002; LeRoith and Roberts, 2003; Renehan et al., 2004; LeRoith and Yakar, 2007). The therapeutic concentrations of insulin are usually below the range required for IGF-1R activation. However if the structure modification of the insulin analogs alters their binding affinity for IGF-1R (Bahr et al., 1997; Slieker et al., 1997; Kurtzhals et al., 2000; Sciacca et al., 2010; Sommerfeld et al., 2010) their mitogenic potential can be increased. Different cell models and different experimental protocols were used to measure analog affinity for IGF-1R overcoming the difficulties due to the interference of the cognate IR. Results were not always concordant.

Among short-acting analogs two out of three studies indicate that lispro has a slightly higher affinity for the IGF-1R in comparison to insulin (Table 3; Kurtzhals et al., 2000), whereas in the other study aspart insulin was found to bind IGF-1R less than insulin (Kurtzhals et al., 2000). In an engineered cell model expressing only the human IGF-1R, the three short-acting analogs bound to this receptor similarly to native insulin (Table 3; Sciacca et al., 2010).

It is today demonstrated that the long-acting insulin analog glargine binds to the IGF-1R with higher affinity than insulin and in some of those studies the increased mitogenic effect of glargine has been attributed to its increased IGF-1R activation. After subcutaneous injection in patients, however, proteolytic degradation of glargine produces two metabolically active metabolites, M1 and M2 (Sommerfeld et al., 2010), which apparently have reduced IGF-1R affinity and reduced mitogenic potency relative to insulin (Sommerfeld et al., 2010). The accurate quantification of glargine metabolites and their ability to stimulate IR isoforms and IGF-1R require further clarification.

The other long-acting insulin analog, detemir, has been studied much less than glargine. In one study the analog interaction with IGF-1R was calculated to be very low, approximately on sixth that of human insulin (Kurtzhals et al., 2000). But in a different model (engineered cells overexpressing IGF-1R and experimental conditions with very low albumin concentration) the two long-acting insulin analogs (detemir and glargine) showed a very similar IGF$1 \mathrm{R}$ binding affinity, for both higher than human insulin (Sciacca et al., 2010). In the same cell model detemir, however, was more potent than glargine in causing IGF-1R phosphorylation (Sciacca et al., 2010).

No data are available on insulin analogs' interactions with hybrid receptors and on their post-receptor signaling after hybrid

Table 3 | Insulin, IGF-1, and insulin analog binding affinity for the IGF-1R.

\begin{tabular}{|c|c|c|c|c|c|c|c|c|}
\hline \multirow[t]{2}{*}{ Cell model (IGF-1R) } & \multirow[t]{2}{*}{ Measurement } & \multirow[t]{2}{*}{ IGF-1 } & \multirow[t]{2}{*}{ Insulin } & \multicolumn{3}{|c|}{ Short-acting analogs } & \multicolumn{2}{|c|}{ Long-acting analogs } \\
\hline & & & & Aspart & Lispro & Glulisine & Glargine & Detemir \\
\hline $\mathrm{R}^{+} / \mathrm{IGF}-1 \mathrm{R}(1)$ & $\mathrm{EC}_{50}(\mathrm{nmol} / \mathrm{l})$ & $2.23 \pm 0.23$ & $>1,000$ & $>1,000$ & $>1,000$ & $>1,000$ & $\approx 300$ & $\approx 300$ \\
\hline 3T3/IGF-1R (2) & $\mathrm{EC}_{50}(\mathrm{nmol} / \mathrm{l})$ & $0.89 \pm 0.19$ & $289 \pm 53.3$ & $/ /$ & // & $/ /$ & $63.2 \pm 19.9$ & $/ /$ \\
\hline $\mathrm{H} 9 \mathrm{c} 2$ (3) & $\mathrm{EC}_{50}(\mathrm{nmol} / \mathrm{l})$ & $/ /$ & $\approx 500$ & $/ /$ & $/ /$ & $/ /$ & $\approx 350$ & $/ /$ \\
\hline HMEC P12 (4) & $\mathrm{EC}_{50}(\mathrm{nmol} / \mathrm{l})$ & $0.42 \pm 0.02$ & $326 \pm 23$ & $/ /$ & $74 \pm 2$ & $/ /$ & // & $/ /$ \\
\hline BHK/IGF-1R (5) & $\%$ & $/ /$ & 100 & $81 \pm 9$ & $156 \pm 16$ & $/ /$ & $641 \pm 51$ & $16 \pm 1$ \\
\hline
\end{tabular}

(1) $R^{+}$/IGF-1R: mouse embryo fibroblasts KO for native IGF-1R and transfected with the human IGF-1R cDNA (Sciacca et al., 2010).

(2) 3T3/IGF-1R: mouse embryo fibroblasts transfected with human IGF-1R (Sommerfeld et al., 2010).

(3) H9c2: rat heart muscle cell line (Bahr et al., 1997).

(4) HMEC P12: human mammary epithelial cells (Slieker et al., 1997).

(5) BHK/IGF-1R: WGA purified receptors from baby hamster kidney cells transfected with the human IGF-1R cDNA (Kurtzhals et al., 2000). 
receptors' activation because of technical difficulties to carry out the necessary experiments.

\section{THE MITOGENIC EFFECTS OF INSULIN ANALOGS ON CANCER CELLS}

The growth-promoting effect of insulin analogs has been manly studied in malignant cell lines. When using malignant cell lines for assessment of insulin activity, insulin effect on cell proliferation must consider that malignant transformation per se affects the cell growth rate via endogenous and exogenous mechanisms and that a remarkable heterogeneity exists between different malignant cell types. In addition to this limitation, the studies on the mitogenic effects of insulin analogs in cancer cells, only few studies have compared the proliferative effect of all insulin analogs in the same cell models. Moreover, the mitogenic effect of insulin analogs has been usually evaluated at supraphysiological doses (50-100 nM). Generally, short-acting insulin analogs stimulated cancer cell proliferation in a similar manner than human insulin (Kurtzhals et al., 2000; Mayer et al., 2008; Shukla et al., 2009; Weinstein et al., 2009) while long-acting analogs stimulate proliferation more than insulin. Although data are not homogeneous and observations on the more recently introduced detemir are scarce, in a variety of cell models both glargine and detemir often show an increased mitogenic response. In particular, in human osteosarcoma cells (Saos-2) that express IGF-1R more than IR, insulin glargine was more potent than native insulin for stimulating growth (Kurtzhals et al., 2000; Sommerfeld et al., 2010). However when insulin glargine metabolites M1 and M2 were evaluated in Saos- 2 cells, their mitogenic effect was similar to that of human insulin (Sommerfeld et al., 2010). When the effects of human insulin, IGF-1, and long-acting insulin analogs glargine and detemir were compared for the stimulation of proliferation in colorectal (HCT-116), prostate (PC-3), and breast (MCF-7) cancer cells, both long-acting analogs stimulated proliferation more than insulin in all three cell lines, but always less than IGF-1 (Weinstein et al., 2009). Other studies found an increased proliferation of
MCF-7 cells induced by glargine (Mayer et al., 2008; Shukla et al., 2009) and that insulin glargine strongly activated the IGF-1R and the mitogen activated protein (MAP) kinase pathway in MCF-7 cells. The predominant role of IGF-1R in mediating this mitogenic effect was suggested by the observation that the proliferative response to insulin glargine was reduced (and equipotent to that of human insulin) in IGF-1R-knockout MCF-7 cells (Shukla et al., 2009). In these cells IR knockdown did not reduce the ability of insulin glargine to activate phosphoinositide 3-kinase (PI3K) and MAPK pathways, in contrast IGF-1R knockdown cognate cells. These results may also been explained by the fact that the studied cells have an IGF-1R/IR ratio greater than 1, suggesting a prevalent role of IGF-1R in mediating the proliferative effect.

The interference of the model and of the procedure heterogeneity is confirmed by the study of insulin glargine on cell growth in the breast cancer MCF-7 and SKBR-3 cells and in the osteosarcoma Saos- 2 cells. No significant differences were found between glargine and human insulin on DNA synthesis, although glargine was slightly more potent than insulin (Liefvendahl and Arnqvist, 2008). Table 4 summarizes the mitogenic effect of insulin analogs in different cancer cells as observed in different studies. The results are expressed as percentage differences in respect to insulin considered as $100 \%$. In addition to variability in the cell model used, also differences in the ligand concentrations studied must be noted.

An important issue concerns the carcinogenic effect of insulin analogs. Cancer initiation (carcinogenesis) indicates the process of malignant transformation of normal cells. Data on this issue are rare. Recently, in non-transformed mouse fibroblasts overexpressing IR-A or IR-B or IGF-1R, neither short-acting nor long-acting insulin analogs stimulated anchorage-independent cell growth (a transformation marker; Sciacca et al., 2010). However, in a previous study in 3T3 fibroblasts overexpressing the IR, insulin dependent formation of colony was observed (Giorgino et al., 1991). Moreover, the increased mitogenic activity elicited by insulin and

Table 4 | In vitro mitogenic effect of insulin analog in cancer cells.

\begin{tabular}{|c|c|c|c|c|c|c|}
\hline \multirow[t]{2}{*}{ Cancer cell line } & \multirow[t]{2}{*}{ Insulin } & \multicolumn{3}{|c|}{ Short-acting analogs } & \multicolumn{2}{|c|}{ Long-acting analogs } \\
\hline & & Aspart & Lispro & Glulisine & Glargine & Detemir \\
\hline MCF-7 (2) & 100 & 100 & 100 & 86 & 133 & 112 \\
\hline T47D (3) & 100 & 100 & 100 & $/ /$ & 100 & 118 \\
\hline MCF-7 (4) & 100 & 100 & 100 & $/ /$ & 140 & 117 \\
\hline PC-3 (6) & 100 & $/ /$ & $/ /$ & $/ /$ & 116 & 114 \\
\hline MCF-7 (7) & 100 & $/ /$ & $/ /$ & $/ /$ & 114 & 106 \\
\hline
\end{tabular}

(1) Saos-2: human osteosarcoma cells. *Estimated potency (Kurtzhals et al., 2000).

(2) MCF-7: human breast cancer cells (Mayer et al., 2008).

(3) T47D: human breast cancer cells (Mayer et al., 2008).

(4) MCF-7: human breast cancer cells (Shukla et al., 2009).

(5) HCT-116: human colorectal cells Weinstein et al., 2009).

(6) PC-3: human prostate cancer (Weinstein et al., 2009).

(7) MCF-7: human breast cancer cells Weinstein et al., 2009). 
its analogs might, per se, increase the risk of errors in DNA duplication and, therefore, cancer initiation.

\section{IN VIVO STUDIES OF INSULIN ANALOGS AND CANCER}

Recent retrospective observational studies using different diabetes registries have published results on cancer association with the use of insulin analogs in diabetic patients (Colhoun, 2009; Currie et al., 2009; Dejgaard et al., 2009; Hemkens et al., 2009; Jonasson et al., 2009). In these studies confounding factors and methodological flaws render the interpretation of results questionable and controversial.

First, in a retrospective cohort study of more than 127,000 patients treated in Germany with either human insulin, lispro, aspart, or insulin glargine for a mean follow-up time of 1.63 years, a dose-dependent association was found between all insulin analogs and cancer incidence (Hemkens et al., 2009). After adjusting for the administered dose, only glargine was related to an increased cancer risk compared to human insulin (HR 1.31 for 50 IU daily dose, $p<0.0001)$. As occurs with all retrospective cohort studies, patients were not randomized to treatment groups and, despite corrections for available confounders, several potentially relevant factors, such as body mass index, duration of diabetes, and smoking habit were not available. Moreover, the follow-up time (1.6 years) was short.

At the same time, on the journal Editor request, data from two additional retrospective observational studies, conducted in Sweden and Scotland, were published in the same journal.

In the Swedish cohort almost 115,000 patients treated with insulin were examined (Jonasson et al., 2009). The risk of developing breast cancer among women receiving insulin glargine monotherapy was significantly higher (RR 1.99, 95\% CI, 1.313.03) than among those using other insulin types. In this study neither randomization nor correction for dose was possible and the risk of developing other forms of cancer was not increased with insulin glargine.

In the Scottish study the national registry data from almost 50,000 insulin treated patients were evaluated (Colhoun, 2009). A small subset $(N=447)$ of patients receiving only insulin glargine was found to have a higher risk of cancer than patients receiving other insulins (RR 1.55, 95\% CI, 1.01-2.37), with a significantly increased risk of breast cancer. The authors explain this result as a possible bias because of the small number of events.

In the same year another retrospective cohort of almost 63,000 patients treated in the United Kingdom with insulin or oral hypoglycemic agents by general practitioners was published (Currie et al., 2009). No significant difference in cancer risk was detected among users of insulin analogs compared with users of human insulin.

Finally in a retrospective, case-control study of insulin treated diabetic patients, cases with incident cancer were associated with a higher dose of insulin glargine (Mannucci et al., 2010). In contrast, no association between increased cancer incidence and insulin dose was found for human insulin or other insulin analogs.

Only one meta-analysis of the Novo Nordisk database of clinical trials has been published on the other long-acting analog detemir (Dejgaard et al., 2009). This meta-analysis was performed in a cohort of 8,693 patients. Patients treated with insulin detemir had a similar occurrence of cancer compared with patients treated with $\mathrm{NPH}$ insulin or insulin glargine. Also this study, as the ones previously mentioned, has a series of limitations including study design, lack of randomization, measured end-point procedures, and, in addition, the small number of patients and the short follow-up time ( 52 weeks).

Although observational studies can usefully detect unexpected drug effects, they may also favor biased conclusions. The problem is that clinical decisions determining each patient's treatment are not random, people are prescribed different therapies for healthrelated reasons. Health outcomes, therefore, might differ between people taking different therapies even if the therapies themselves have no such effect. Despite adjustment for confounders, residual selection bias might distort true differences between treatments. As patients' diabetes progresses, their mortality risk increases. Moreover, poor glycemic control might prompt the introduction of insulin, creating systematic differences between patients receiving oral antidiabetic drugs or insulin and adding confounding factors related not only to drug differences but also to patient metabolic and general situation when therapy was selected. Higher doses of insulin required by the poor metabolic control will be linked to higher mortality due to other reasons, an artifact of treatment change as disease advances, rather than actual treatment effects. Another issue is reverse causality: cancer often has a long period between biological onset and clinical diagnosis. During the subclinical phase, insulin requirements might be affected by the undetected cancer, and lead to treatment changes. To the unwary observer, this treatment change can appear as favoring cancer, when vice versa it is cancer that produces treatment change (Pocock and Smeeth, 2009).

As already mentioned, therefore, the available clinical evidence can neither demonstrate nor exclude an increased risk of cancer in diabetic patients treated with insulin analogs. The evidence reported for glargine is not only weak but also strongly criticizable and controversial. No independent study is available for detemir. The concern, therefore, cannot be excluded also because the possibility of an increased mitogenic effect is supported by numerous in vitro studies.

\section{CONCLUSION}

The question of an increased mitogenic effect, in vitro and in vivo, of modified insulin analogs remains open.

In vitro results indicate an increased relative mitogenic potency of long-acting insulin analogs relative to insulin. Evidence strength is limited by the use of malignant cells, of supraphysiological concentrations of ligands and also by much possible interference in the experimental procedures. Even if an increased mitogenic activity of these analogs is admitted in vitro, this does not necessarily represent what happens when insulin analogs are administered to patients (Kurtzhals et al., 2000; Mayer et al., 2008; Shukla et al., 2009; Weinstein et al., 2009; Sciacca et al., 2010; Sommerfeld et al., 2010). In vivo injected analog distribution, metabolism, and clearance may be very different. For instance, glargine is transformed into M1 and M2 metabolites (Sommerfeld et al., 2010) and detemir is strongly bound to albumin. Moreover, different tissues will respond differently on the basis of the quantity and the quality of the receptors expressed. Retrospective epidemiological 
studies on the risk of cancer in patients treated with insulin analogs are scientifically weak and controversial. Prospective trials are not available, difficult to design because of the heterogeneity of the diabetic population and the number of confounding factors, and very unlikely to be performed in the next future. Since an increased risk of cancer associated with insulin analogs therapy cannot be excluded, strict surveillance and studies with new approaches and with long-term follow up are needed.

\section{REFERENCES}

Avnet, S., Sciacca, L., Salerno, M., Gancitano, G., Cassarino, M. F., Longhi, A., Zakikhani, M., Carboni, J. M., Gottardis, M., Giunti, A., Pollak, M., Vigneri, R., and Baldini, N. (2009). Insulin receptor isoform A and insulin-like growth factor II as additional treatment targets in human osteosarcoma. Cancer Res. 69, 2443-2452.

Bahr, M., Kolter, T., Seipke, G., and Eckel, J. (1997). Growth promoting and metabolic activity of the human insulin analogue [GlyA21,ArgB31,ArgB32] insulin (HOE 901) in muscle cells. Eur. J. Pharmacol. 320, 259-265.

Becker, R. H. (2007). Insulin glulisine complementing basal insulins: a review of structure and activity. Diabetes Technol. Ther. 9, 109-121.

Becker, R. H., and Frick, A. D. (2008). Clinical pharmacokinetics and pharmacodynamics of insulin glulisine. Clin. Pharmacokinet. 47, 7-20.

Belfiore, A., Frasca, F., Pandini, G., Sciacca, L., and Vigneri, R. (2009). Insulin receptor isoforms and insulin receptor/insulin-like growth factor receptor hybrids in physiology and disease. Endocr. Rev. 30, 586-623.

Berti, L., Kellerer, M., Bossenmaier, B., Seffer, E., Seipke, G., and Haring, H. U. (1998). The long acting human insulin analog HOE 901: characteristics of insulin signalling in comparison to $\operatorname{Asp}(\mathrm{B} 10)$ and regular insulin. Horm. Metab. Res. 30, 123-129.

Blanquart, C., Achi, J., and Issad, T. (2008). Characterization of IRA/IRB hybrid insulin receptors using bioluminescence resonance energy transfer. Biochem. Pharmacol. 76, 873-883.

Bolli, G. B., Di Marchi, R. D., Park, G. D., Pramming, S., and Koivisto, V. A. (1999). Insulin analogues and their potential in the management of diabetes mellitus. Diabetologia 42, 1151-1167.

Brems, D. N., Alter, L. A., Beckage, M. J., Chance, R. E., Dimarchi, R. D., Green, L. K., Long, H. B., Pekar, A. H., Shields, J. E., and Frank, B. H. (1992). Altering the association properties of insulin by amino acid replacement. Protein Eng. 5, 527-533.

Ciaraldi, T. P., Carter, L., Seipke, G., Mudaliar, S., and Henry, R. R.
(2001). Effects of the long-acting insulin analog insulin glargine on cultured human skeletal muscle cells: comparisons to insulin and IGF-I. J. Clin. Endocrinol. Metab. 86, 5838-5847.

Colhoun, H. M. (2009). Use of insulin glargine and cancer incidence in Scotland: a study from the Scottish Diabetes Research Network Epidemiology Group. Diabetologia 52, 1755-1765.

Currie, C. J., Poole, C. D., and Gale, E. A. (2009). The influence of glucoselowering therapies on cancer risk in type 2 diabetes. Diabetologia 52, 1766-1777.

Dejgaard, A., Lynggaard, H., Rastam, J., and Krogsgaard Thomsen, M. (2009). No evidence of increased risk of malignancies in patients with diabetes treated with insulin detemir: a meta-analysis. Diabetologia 52, 2507-2512.

Dideriksen, L. H., Jorgensen, J. L. N., and Drejer, K. (1992). Carcinogenic effect on female rats after 12 months administration of the insulin analog B10 Asp. Diabetes 41, 143A.

Drejer, K. (1992). The bioactivity of insulin analogues from in vitro receptor binding to in vivo glucose uptake. Diabetes Metab. Rev. 8 , 259-285.

Ebeling, P., Tuominen, J. A., and Koivisto, V. A. (1996). Insulin analogues and carcinoma of the breast. Diabetologia 39, 124-125.

Frasca, F., Pandini, G., Scalia, P., Sciacca, L., Mineo, R., Costantino, A., Goldfine, I. D., Belfiore, A., and Vigneri, R. (1999). Insulin receptor isoform $\mathrm{A}$, a newly recognized, highaffinity insulin-like growth factor II receptor in fetal and cancer cells. Mol. Cell. Biol. 19, 3278-3288.

Furstenberger, G., and Senn, H. J. (2002). Insulin-like growth factors and cancer. Lancet Oncol. 3, 298-302.

Giorgino, F., Belfiore, A., Milazzo, G., Costantino, A., Maddux, B., Whittaker, J., Goldfine, I. D., and Vigneri, R. (1991). Overexpression of insulin receptors in fibroblast and ovary cells induces a ligandmediated transformed phenotype. Mol. Endocrinol. 5, 452-459.

Hansen, B. F., Danielsen, G. M., Drejer, K., Sorensen, A. R., Wiberg, F. C., Klein, H. H., and Lundemose, A. G. (1996). Sustained signalling from the insulin receptor after stimulation with insulin analogues exhibiting increased mitogenic potency. Biochem. J. 315(Pt 1), 271-279.

Heinemann, L., Weyer, C., Rauhaus, M., Heinrichs, S., and Heise, T. (1998). Variability of the metabolic effect of soluble insulin and the rapidacting insulin analog insulin aspart. Diabetes Care 21, 1910-1914.

Heise, T., Bott, S., Rave, K., Dressler, A., Rosskamp, R., and Heinemann, L. (2002). No evidence for accumulation of insulin glargine (LANTUS): a multiple injection study in patients with Type 1 diabetes. Diabet. Med. 19, 490-495.

Hemkens, L. G., Grouven, U., Bender, R. Gunster, C., Gutschmidt, S., Selke, G. W., and Sawicki, P. T. (2009). Risk of malignancies in patients with diabetes treated with human insulin or insulin analogues: a cohort study. Diabetologia 52, 1732-1744.

Hennige, A. M., Strack, V., Metzinger, E., Seipke, G., Haring, H. U., and Kellerer, M. (2005). Effects of new insulin analogues HMR1964 (insulin glulisine) and HMR1423 on insulin receptors. Diabetologia 48 1891-1897.

Hirsch, I. B. (2005). Insulin analogues. N. Engl. J. Med. 352, 174-183.

Holleman, F., and Hoekstra, J. B. (1997). Insulin lispro. N. Engl. J. Med. 337, 176-183.

Howey, D. C., Bowsher, R. R., Brunelle, R. L., and Woodworth, J. R. (1994). [Lys(B28), Pro(B29)]-human insulin. A rapidly absorbed analogue of human insulin. Diabetes 43, 396-402.

Ish-Shalom, D., Christoffersen, C. T., Vorwerk, P., Sacerdoti-Sierra, N., Shymko, R. M., Naor, D., and De Meyts, P. (1997). Mitogenic properties of insulin and insulin analogues mediated by the insulin receptor. Diabetologia 40(Suppl. 2), S25-S31.

Jensen, M., and De Meyts, P. (2009). Molecular mechanisms of differential intracellular signaling from the insulin receptor. Vitam. Horm. 80, 51-75.

Johnson, J. A., and Gale, E. A. (2010). Diabetes, insulin use, and cancer risk: are observational studies part of the solution-or part of the problem? Diabetes 59, 1129-1131.

Jonasson, J. M., Ljung, R., Talback, M., Haglund, B., Gudbjornsdottir, S., and Steineck, G. (2009).
Insulin glargine use and shortterm incidence of malignancies-a population-based follow-up study in Sweden. Diabetologia 52, 1745-1754.

Kalli, K. R., Falowo, O. I., Bale, L. K., Zschunke, M. A., Roche, P. C., and Conover, C. A. (2002). Functional insulin receptors on human epithelial ovarian carcinoma cells: implications for IGF-II mitogenic signaling. Endocrinology 143, 3259-3267.

Kurtzhals, P., Havelund, S., Jonassen, I., and Markussen, J. (1997). Effect of fatty acids and selected drugs on the albumin binding of a long-acting, acylated insulin analogue. J. Pharm. Sci. 86, 1365-1368.

Kurtzhals, P., Schaffer, L., Sorensen, A., Kristensen, C., Jonassen, I., Schmid, C., and Trub, T. (2000). Correlations of receptor binding and metabolic and mitogenic potencies of insulin analogs designed for clinical use. Diabetes 49 , 999-1005.

Lepore, M., Pampanelli, S., Fanelli, C., Porcellati, F., Bartocci, L., Di Vincenzo, A., Cordoni, C., Costa, E., Brunetti, P., and Bolli, G. B. (2000). Pharmacokinetics and pharmacodynamics of subcutaneous injection of long-acting human insulin analog glargine, NPH insulin, and ultralente human insulin and continuous subcutaneous infusion of insulin lispro. Diabetes 49, 2142-2148.

LeRoith, D., and Yakar, S. (2007). Mechanisms of disease: metabolic effects of growth hormone and insulin-like growth factor 1. Nat. Clin. Pract. Endocrinol. Metab. 3, 302-310.

LeRoith, D., and Roberts, C. T. Jr. (2003). The insulin-like growth factor system and cancer. Cancer Lett. 195, 127-137.

Liefvendahl, E., and Arnqvist, H. J. (2008). Mitogenic effect of the insulin analogue glargine in malignant cells in comparison with insulin and IGF-I. Horm. Metab. Res. 40, 369-374.

Mannucci, E., Monami, M., Balzi, D., Cresci, B., Pala, L., Melani, C., Lamanna, C., Bracali, I., Bigiarini, M., Barchielli, A., Marchionni, N., and Rotella, C. M. (2010). Doses of insulin and its analogues and cancer occurrence in insulin-treated type 2 diabetic patients. Diabetes Care 33, 1997-2003. 
Markussen, J., Havelund, S., Kurtzhals, P., Andersen, A. S., Halstrom, J., Hasselager, E., Larsen, U. D., Ribel, U., Schaffer, L., Vad, K., and Jonassen, I. (1996). Soluble, fatty acid acylated insulins bind to albumin and show protracted action in pigs. Diabetologia 39, 281-288.

Mayer, D., Shukla, A., and Enzmann, H. (2008). Proliferative effects of insulin analogues on mammary epithelial cells. Arch. Physiol. Biochem. 114, 38-44.

Milazzo, G., Sciacca, L., Papa, V., Goldfine, I. D., and Vigneri, R. (1997). ASPB10 insulin induction of increased mitogenic responses and phenotypic changes in human breast epithelial cells: evidence for enhanced interactions with the insulin-like growth factor-I receptor. Mol. Carcinog. 18, 19-25.

Mosthaf, L., Grako, K., Dull, T. J., Coussens, L., Ullrich, A., and Mcclain, D. A. (1990). Functionally distinct insulin receptors generated by tissue-specific alternative splicing. EMBO J. 9, 2409-2413.

Moxham, C. P., Duronio, V., and Jacobs, S. (1989). Insulin-like growth factor I receptor beta-subunit heterogeneity. Evidence for hybrid tetramers composed of insulin-like growth factor I and insulin receptor heterodimers. J. Biol. Chem. 264, 13238-13244.

Owens, D. R., Coates, P. A., Luzio, S. D., Tinbergen, J. P., and Kurzhals, R. (2000). Pharmacokinetics of 125Ilabeled insulin glargine (HOE 901) in healthy men: comparison with $\mathrm{NPH}$ insulin and the influence of different subcutaneous injection sites. Diabetes Care 23, 813-819.

Papa, V., Pezzino, V., Costantino, A., Belfiore, A., Giuffrida, D., Frittitta, L., Vannelli, G. B., Brand, R., Goldfine, I. D., and Vigneri,
R. (1990). Elevated insulin receptor content in human breast cancer. $J$. Clin. Invest. 86, 1503-1510.

Plank, J., Wutte, A., Brunner, G., Siebenhofer, A., Semlitsch, B., Sommer, R., Hirschberger, S., and Pieber, T. R. (2002). A direct comparison of insulin aspart and insulin lispro in patients with type 1 diabetes. Diabetes Care 25, 2053-2057.

Pocock, S. J., and Smeeth, L. (2009). Insulin glargine and malignancy: an unwarranted alarm. Lancet 374, 511-513.

Rakatzi, I., Ramrath, S., Ledwig, D., Dransfeld, O., Bartels, T., Seipke, G., and Eckel, J. (2003). A novel insulin analog with unique properties: LysB3,GluB29 insulin induces prominent activation of insulin receptor substrate 2 , but marginal phosphorylation of insulin receptor substrate 1. Diabetes 52, 2227-2238.

Renehan, A. G., Zwahlen, M., Minder, C., O'Dwyer, S. T., Shalet, S. M., and Egger, M. (2004). Insulin-like growth factor (IGF)-I, IGF binding protein-3, and cancer risk: systematic review and meta-regression analysis. Lancet 363, 1346-1353.

Sciacca, L., Cassarino, M. F., Genua, M., Pandini, G., Le Moli, R., Squatrito, S., and Vigneri, R. (2010). Insulin analogues differently activate insulin receptor isoforms and postreceptor signalling. Diabetologia 53, 1743-1753.

Sciacca, L., Costantino, A., Pandini, G., Mineo, R., Frasca, F., Scalia, P., Sbraccia, P., Goldfine, I. D., Vigneri, R., and Belfiore, A. (1999). Insulin receptor activation by IGFII in breast cancers: evidence for a new autocrine/paracrine mechanism. Oncogene 18, 2471-2479.

Shukla, A., Grisouard, J., Ehemann, V., Hermani, A., Enzmann, H., and Mayer, D. (2009). Analysis of signaling pathways related to cell proliferation stimulated by insulin analogs in human mammary epithelial cell lines. Endocr. Relat. Cancer 16, 429-441.

Simpson, K. L., and Spencer, C. M. (1999). Insulin aspart. Drugs 57, 759-65; discussion 766-767.

Slieker, L. J., Brooke, G. S., Dimarchi, R. D., Flora, D. B., Green, L. K., Hoffmann, J. A., Long, H. B., Fan, L., Shields, J. E., Sundell, K. L. Surface, P. L., and Chance, R. E. (1997). Modifications in the B10 and B26-30 regions of the $B$ chain of human insulin alter affinity for the human IGF-I receptor more than for the insulin receptor. Diabetologia 40(Suppl. 2), S54-S61.

Slieker, L. J., and Sundell, K. (1991) Modifications in the 28-29 position of the insulin B-chain alter binding to the IGF-I receptor with minimal effect on insulin receptor binding. Diabetes 40(Suppl. 1), 168A.

Smith, U., and Gale, E. A. (2009). Does diabetes therapy influence the risk of cancer? Diabetologia 52, 1699-1708.

Sommerfeld, M. R., Muller, G., Tschank, G., Seipke, G., Habermann, P., Kurrle, R., and Tennagels, N. (2010) In vitro metabolic and mitogenic signaling of insulin glargine and its metabolites. PLoS ONE 5, e9540. doi:10.1371/journal.pone.0009540

Staiger, K., Hennige, A. M., Staiger, H., Haring, H. U., and Kellerer, M. (2007). Comparison of the mitogenic potency of regular human insulin and its analogue glargine in normal and transformed human breast epithelial cells. Horm. Metab. Res. 39, 65-67.

Vajo, Z., Fawcett, J., and Duckworth, W. C. (2001). Recombinant DNA technology in the treatment of diabetes: insulin analogs. Endocr. Rev. 22, 706-717.
Vella, V., Pandini, G., Sciacca, L., Mineo, R., Vigneri, R., Pezzino, V., and Belfiore, A. (2002). A novel autocrine loop involving IGF-II and the insulin receptor isoform-A stimulates growth of thyroid cancer. J. Clin. Endocrinol. Metab. 87, 245-254.

Vigneri, P., Frasca, F., Sciacca, L., Frittitta, L., and Vigneri, R. (2006). Obesity and cancer. Nutr. Metab. Cardiovasc. Dis. 16, 1-7.

Vigneri, P., Frasca, F., Sciacca, L., Pandini, G., and Vigneri, R. (2009) Diabetes and cancer. Endocr. Relat. Cancer 16, 1103-1123.

Weinstein, D., Simon, M., Yehezkel, E., Laron, Z., and Werner, H. (2009). Insulin analogues display IGF-I-like mitogenic and anti-apoptotic activities in cultured cancer cells. Diabetes Metab. Res. Rev. 25, 41-49.

Conflict of Interest Statement: The authors declare that the research was conducted in the absence of any commercial or financial relationships that could be construed as a potential conflict of interest.

Received: 30 September 2011; accepted: 24 January 2012; published online: 10 February 2012.

Citation: Sciacca L, Le Moli $R$ and Vigneri $R$ (2012) Insulin analogs and cancer. Front. Endocrin. 3:21. doi: 10.3389/fendo.2012.00021

This article was submitted to Frontiers in Cancer Endocrinology, a specialty of Frontiers in Endocrinology.

Copyright (C) 2012 Sciacca, Le Moli and Vigneri. This is an open-access article distributed under the terms of the Creative Commons Attribution Non Commercial License, which permits noncommercial use, distribution, and reproduction in other forums, provided the original authors and source are credited. 